\title{
Developmental Anomalies in Domestic Mammals and the One Health Concept
}

\author{
I Salazar* \\ Department of Anatomy and Animal Production, Unit of Anatomy and Embryology, University of Santiago de \\ Compostela, Spain
}

\begin{abstract}
Rudolf Virchow, considered by many the Father of Pathology, established a clear link between human and animal health. From that idea emerged the "one medicine" concept, which evolved into "one health" concept many years later. Nevertheless, only recently has there been a renewed interest in the subject, and this for three main reasons: i) The recognition that an extraordinary high percentage of infectious diseases in human were zoonosis; ii) The advances in the knowledge of the genome in man and animals; iii) The huge and rapid scientific progress achieved in recent years in the medical field. Time has come for physicians and veterinarians to recognize the value of the close relationship between human and veterinary medicine. Here, after a brief summary of the meaning of "one health" concept, and following a strict morphological approach - revolving around the life cycle, anatomy of development, failures of the system and domestic mammals - I report that there is enough evidence for considering that the developmental anomalies are relevant health issues for man and animals. Therefore, I suggest that such exciting and complex subject definitively integrates the "one health" concept.
\end{abstract}

Keywords

Human health, Veterinary health, “One medicine”, Anatomy of development, Malformations

\section{Introduction}

Most experts in health are strongly convinced of the close relationship between human and veterinary medicine, and that benefits arisen from such connection may result very noticeable when analysed in the right context [1-3]. The relevance of this conception has been highlighted by several international organisms. The World Health Organization (WHO), the World Organisation for Animal Health (Office International des Epizooties, OIE), the Food and Agriculture Organization of the United Nations (FAO), the American Medical Association (AMA) and the American Veterinary Medical Association (AVMA) [4-6], to cite some of the most relevant, have pointed out its importance.

Many sources may help prove the truthfulness of the relation referred. The most objective data probably comes from a singular dimension of the disease itself: its transmission from animals to humans, or classical zoonosis [7-9], and from humans to animals, or zooanthroponosis [10].

Other equally interesting, relevant and illustrative ap- proaches are animal testing, animal transplantation and animal research [11], which have led, among other achievements, to the transplantation of organs from animals to man or xenotransplantation [12,13]. Especially relevant are the cases where pigs are used as donors [14-16]. The progress made in understanding the genome of man and other species has helped to bring together, and strengthen, the relationship between human and veterinary medicine $[17,18]$.

Some medical specialities that could provide valuable additional approaches are unfortunately not being taken into account. One of them is the presentation of malformations, dysmorphias or anomalies [19-22], which is a

*Corresponding author: I Salazar, Department of Anatomy and Animal Production, Unit of Anatomy and Embryology, Faculty of Veterinary, University of Santiago de Compostela, Av Carballo Calero s/n, 27002 Lugo, Spain, E-mail: ignacio.salazar@usc.es

Received: March 27, 2017; Accepted: June 30, 2017; Published online: July 03, 2017

Citation: Salazar I (2017) Developmental Anomalies in Domestic Mammals and the One Health Concept. Stud Anat Physiol 1(1):5-12

Copyright: (C) 2017 Salazar I. This is an open-access article distributed under the terms of the Creative Commons Attribution License, which permits unrestricted use, distribution, and reproduction in any medium, provided the original author and source are credited. 
well-studied subject in human medicine, not so thoroughly treated in veterinary medicine, and less of all from a comparative point of view.

The present article addresses several particularities of malformations in the context of veterinary science, more specifically in the field of domestic mammals, from the "one health" concept perspective.

\section{"One Health" Concept}

At the end of the nineteenth century, the eminent pathologist Rudolf Virchow had the conviction that it was necessary to establish a solid link between human and veterinary medicine [23]. Virchow argued that "between animal and human medicine there are no dividing lines - nor should there be. The object is different but the experience obtained constitutes the basis of all medicine" [24]. Virchow's idea was assumed by many of his students, who became committed to disclosing it, and one of them - William Osler - coined the expression "one medicine" [25]. Nonetheless, Calvin Schwabe is the author credited for the rebirth of the modern "one medicine" movement [26].

Despite the effort done by distinguished physicians and veterinarians to convince their colleagues of the importance of developing Virchow's idea, it remains unnoticed over decades. In the XXI century, however, there is strong evidence to believe that approximately $75 \%$ of new emerging human infectious diseases are zoonotic [7]. The subject began to be taken seriously and some professional groups became aware of its relevance [27]. As a result, it was suggested that "one medicine" revival strategies should involve medical and veterinary education, clinical care, public health and biomedical research [9].

New ideas on the subject start piercing, drawing the "one medicine" idea to evolve over time, thus leading to the emergence of new terminologies, among which "one health" was broadly accepted. Some authors suggested that the "one health" concept should be considered at the same level of importance as any of the practical methods belonging to the field of integrated disease surveillance, joint animal-human epidemiological studies and health services development. This is expected to serve as a discussion basis for mutually agreed practical cooperation between human and animal health [3]. In other words, "one health" could be defined as a collaborative effort among multiple disciplines working locally, nationally and globally to attain optimal health for people, animals and the environment [28].

It is equally true that "one health" was not the only novel paradigm appearing from the original "one medicine". For instance, the "eco health" or "ecosystem health" which, theoretically at less, goes far beyond the health- care field [29-31]. This has caused some controversy concerning the conceptual meaning of the different paradigms used [32-34], although it is generally assumed that there is a conceptual convergence between "one health" and "eco health" [35,36].

In this article, "one health" has been chosen as preferred term, even allowing that it is a holistic concept, because it clearly reflects the original Virchow notion [37-39] and avoids getting into discussions that belong way beyond the scope of the present work.

\section{Life Cycle and Anatomy of Development}

An easy way to understand the meaning of the malformations in veterinary science consists in analysing some basic, general and essential concepts of the life cycle [40], which could be represented by the typical Gaussian curve, projected onto a Cartesian coordinate system (Supplementary data 1.1). To achieve what is intended in this section, the curve in question needs to be modified, in this case by drawing segments on it. The zero-zero point of the system corresponds to fecundation (fertilization), and from there onwards there is a series of phases, clearly distinguishable from one another before birth, and diffuse after birth. Before birth, the divisions into germinal, embryonic or organogenetic, and foetal periods are evident. After birth, the only well-defined phase is between birth and puberty, after which it is no longer possible to establish properly defined stretches of time with in adult period; the adult organism undergoes senescence and dies (Supplementary data 1.2). Some changes will be introduced in the representation of the life cycle at the moment of reaching puberty, when animals have the ability to procreate. Therefore, the graph of an individual organism leads to one showing the true concept of the cycle, which encompasses the whole species. This change requires considering the addition of an extra phase, the gametogenesis.

The gametogenesis, or development of gametes, is an essential requirement for fertilization and has been represented before the zero-zero coordinates of the system, albeit there are certain connotations worthy to be mentioned. Firstly, and most relevant concerning the primordial germ cells, or precursor gametes cells, which are formed during the blastula sub-period, perform migration and finally colonize the gonadal ridge, where they evolve to female or male gametes. The use of different types of arrows has been found useful to make the corresponding representation, resulting a "vital adapted cycle" (Supplementary data 1.3).

Some important issues drawn from the "vital adapted cycle" are briefly commented next, for the time lapse between fecundation and puberty, paying most exhaustive attention to the morphological events. The cellular activity during the germinal period, which starts with the first segmentation division, leads to successive cleavages, the formation of a 
morula, a blastula and then a gastrula, which is equivalent to a trilaminar germ. From this early germ, the three layers of metazoan are finally defined: ectoderm, mesoderm and endoderm. That means that the organism, in this first period of the cycle, undergoes a series of changes that may be called "creative variations". Changes of this type are also common during the embryonic period, although by then it is already possible to differentiate tissues and later on organs.

Changes will continue occurring after the embryonic period, although they are of different nature from foetal period onwards: now the organism mainly grows and the previously formed structures are strengthened. These changes are referred to as "growth variations"; and continue happening after birth until puberty (Supplementary data 1.4).

Any reasonable conceptual approach states that between fecundation and birth a new organism is being constituted and organized. That means that, from a strictly morphological point of view, the developmental anatomy should be, during this stage, the speciality in charge of the analysis of the subsequent changes occurring and the report of them through the appropriate descriptions.

Such descriptions are addressed by classical and new text books of human embryology [41-44] and veterinary embryology [45-48]. Other authors who approach embryology in a multidisciplinary way recognize that "the basis of all research in developmental biology is the changing anatomy of the organism" [49].

The continuous morphological events that happen during the different periods of the life cycle are regulated by a systematically repeated complex molecular mechanism [50-54]. Before birth, such mechanism controls those changes, regardless of the type. The causal embryology or molecular embryology is the discipline in charge of its study [55-57]. Unfortunately, the functioning of the molecular mechanism is not always perfect and eventually miss-reads its own code, more frequently than we could expect and hope [58]. The mistakes made by the code are responsible, on the one hand (before birth), for the incidence of defects or failures in the programmed morphogenesis (see below) and, on the other hand (after birth), for the occurrence of diseases.

\section{Developmental Anomalies}

For morphologists Dysmorphia is, in a broad sense, an official term to design any abnormality in the shape or other features of a body part. The initial idea when undertaking the building up of the Terminologia Embryologica $[59,60]$ was, and still is, to compile the most comprehensive list of dysmorphias as a Nomina dysmorphica. However, in view of the magnitude of the problem, the initial strategy does not fulfil satisfactory all the needs of such laborious task, and alternative approaches have been suggested, as to go step by step. Dysmorphias have been classified into different organic systems, to subsequently make a representative selection within each category and a list of them [61,62].

Two main issues still add difficulty to the subject. In the first place, the frequent use of alternative terms like congenital abnormality, congenital defects, congenital malformation, developmental dysfunction, developmental field defects, malformation, and so on. Those terms have the same or a similar meaning to dysmorphia; nonetheless, in some instances their use causes confusion or controversy, mainly when attempting semantic or terminological classifications [63-68]. Secondly, it is patent that dysmorphology has currently developed into a separate specialty, as is evidenced by the extraordinary number of dysmorphic syndromes contained in the Winter-Braitser Dysmorphology Database [69].

For these reasons, and willing to facilitate the understanding of the approach presented in the previous section, "Developmental Anomalies" (DA) is the chosen term in this article to refer to any kind of malformation occurring during development. The key point for studying and correctly grasping the DA is directly related to the exact meaning of the errors made by the molecular mechanism regulating the development [58,60]. Such errors -from now on system errors- lead to the occurrence of DA, as previously quoted.

The presentation of DA is usually considered to happen due to internal and external etiological agents. The relationship between internal causes and system errors is more than obvious, but when analysing external causes, it is pertinent to bring about some nuances. External causes are linked to different environmental influences: physical factors (radiations, temperature, hypoxia, noises), chemical factors (side-effects of pharmaceutical products), chemical and industrial pollutants (fungicides, herbicides, insecticides, pesticides), food and nutrition problems (malnutrition, vitamin and mineral deficiency, ingestion of poisonous plants), infectious agents (protozoa, fungi, bacteria, virus), and other factors [40]. In any of those cases, the mother is the affected subject, and the problem is transferred to the embryo/foetus through the placenta, giving way in each case to different types of malformations. Hence, system errors occur during different stages of the life cycle, always after the puberty, but at two levels: the mother and the placental barrier [70,71].

When looking for a strategy to classify the DA, we might encounter similar or even bigger difficulties than the previously commented for the case of dysmorphias. However, it seems pertinent to highlight the magnitude of the matter, from undetected earliest stages (embryos 
reabsorption, certain miscarriages) to true monstrosities (cyclopia, cephalophagus). Within these two edges, there is an enormous variety of DA (system errors), many of which are undetected either externally or macroscopically (different syndromes of the nervous system and sense organs).

Several approaches can be used to give an idea of the complexity and extent of the matter, and one of them is quite appreciated by the students of embryology in our Veterinary School. It is a question of allowing the students to experience by themselves the mistakes that can be made when carrying out an easy mathematical calculation. The exercise proposed is the following: starting with twelve numbers of one, two or three digits, the students must perform sequential simple calculations, previously scheduled (such as additions, subtractions, multiplications and divisions), with the aim to get a final result of eight digits rounded down to eight decimal places. When done with the calculation, the students must analyse the consequences the mistakes made, if any, on the final number they obtained and then, determine if the magnitude of the error concerns decimal places or units, tens, hundreds, units of thousand, tens of thousands, etc. They will finally draw up the analogies they deem relevant in relation to the series of system errors involved within development. The conclusions reached by the students were very interesting (unpublished data).

\section{Domestic Mammals}

In the context of the present article, Domestic Mammals (DM) shall mean a group of animals including cows, sheep, goats, pigs, horses, dogs and cats. Among several reasons, this section is only focused on the DM mainly because of three important facts: i) Their close relationship with humans, ii) The high percentage of DA they have in common with humans; iii) They are the best studied species in veterinary profession. Using a specific group of animals, in this particular case the DM, the one health concept is thought to be easier to apply and more objectively achievable.

Furthermore, and because the one health concept goes beyond the dimension of the strictly healthcare-related, the presentation of DA in DM produces different types of negative effects: economic, environmental, emotional, and so on, with greater or lower impact depending on the nature of the DA in question and the species suffering from it.

The anomalies that have traditionally drawn the attention of the specialists are those showing macroscopic and external symptoms, and more particularly major malformations or monstrosities (see embryology text books previously cited). It is widely agreed that ruminants and pigs belong to a group called production animals or an-
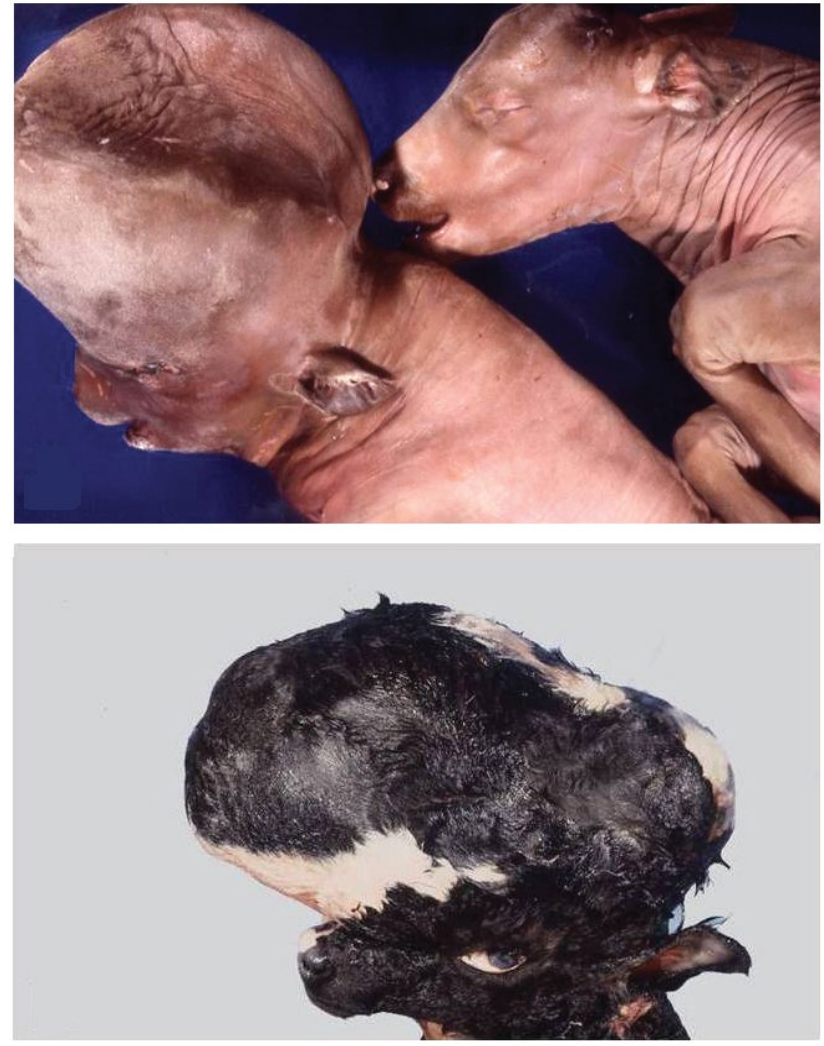

Figure 1: Lateral view of two different cases of hydrocephalus in cattle, showing marked enlargement of the head. Top, shows the head size in two unborn litter mates.

imals for slaughter, horses are mainly used for sport and leisure purposes, and dogs and cats are pet or companion animals. Since the breeding and rearing system is also different for each species, the effects of DA -not counting the effects on health, of equal nuisance to all animals -could be summarized as: for production animals the biggest will be economic and environmental impacts; for horses, economic and emotional impacts; for pets, emotional impact.

As mentioned above, the DA in veterinary science have not been subject of exhaustive study in the field of DM, although there are enough well documented cases [46,72], many of which are common to humans. Four examples, found with relative frequency in cows, have been chosen from our collection: hydrocephalus (Figure 1), bicephalous (Figure 2), cleft palate or palatoschisis (Figure 3), and congenital flexed pastern (Figure 3), the last one described in humans as congenital wrist flexion contracture, a kind of arthrogryposis.

A particular boost to the original Virchow's idea, and consequently to "one health" concept, was provided by the advances in knowledge of the genome of different species. In that regard, dogs have been considered an excellent model among mammals [73-75] for mapping both simple and complex traits and diseases [76,77]. Several authors have put an increasing emphasis on it [78-80], and Elaine 


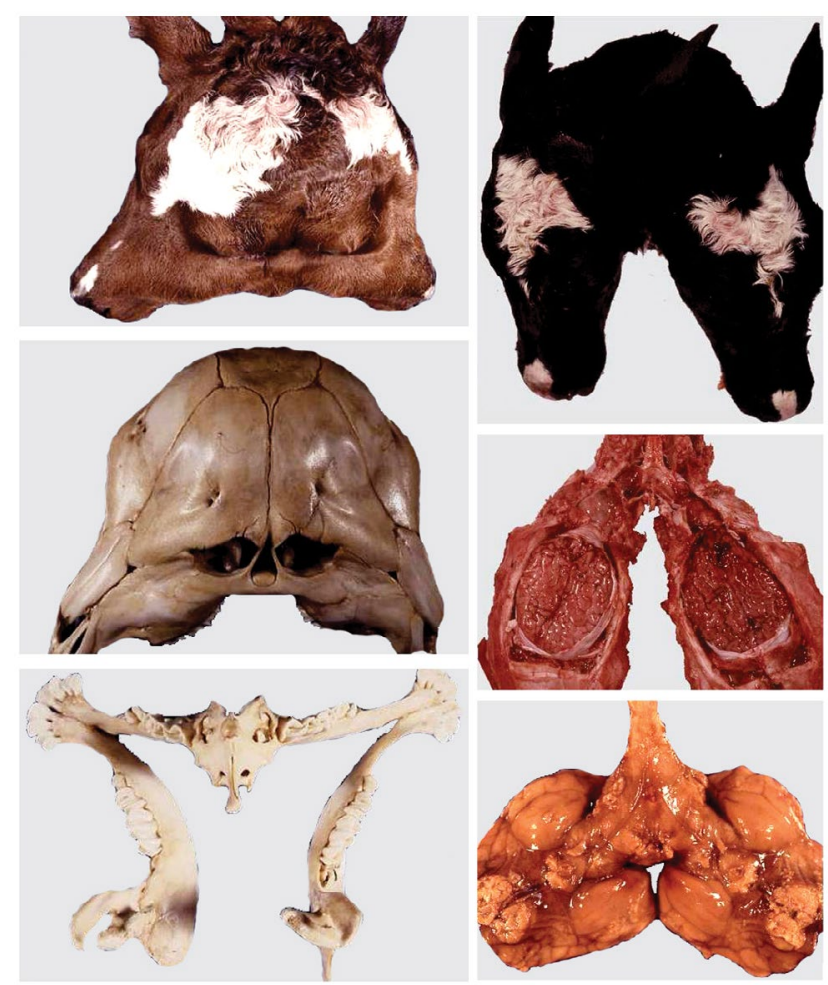

Figure 2: Two different cases of bicephalous or two-headed in cattle, showing the external head and skeleton (left), and the external head and superior and inferior view of the brain (right).

Ostrander has clearly expressed the key point [81]: for nearly 350 years, veterinary medicine and human medicine have been separate entities, with one geared toward the diagnosis and treatment in animals and the other toward parallel goals in the owners. However, that model no longer fits, since research on diseases of humans and companion animals has coalesced. The catalyst for this union has been the completion of the human genome sequence $[82,83]$, coupled with draft sequence assemblies of the genome of dogs [84].

Concurrently, the study of the dog genome has provided a lot of relevant information, closely related to the presentation of certain DA due to breeding genetic propensity or predisposition (Canine Inherited Disorders Database [85], Guide to Congenital and Heritable Disorders in Dogs [86], Inherited Diseases in Dogs [87], List of Inherited Disorders in Animals [88], Online Mendelian Inheritance in Animals database [89]). The importance of this matter has led to the strengthening of certain international projects, as for example the LUPA project [90] whose data are updated periodically since its inception [91].

It is important to bear in mind that the estimated number of breeds of dogs is of over 400, of which around a half are officially recognized $[92,93]$. This enormous diversity of breeds means that during domestication
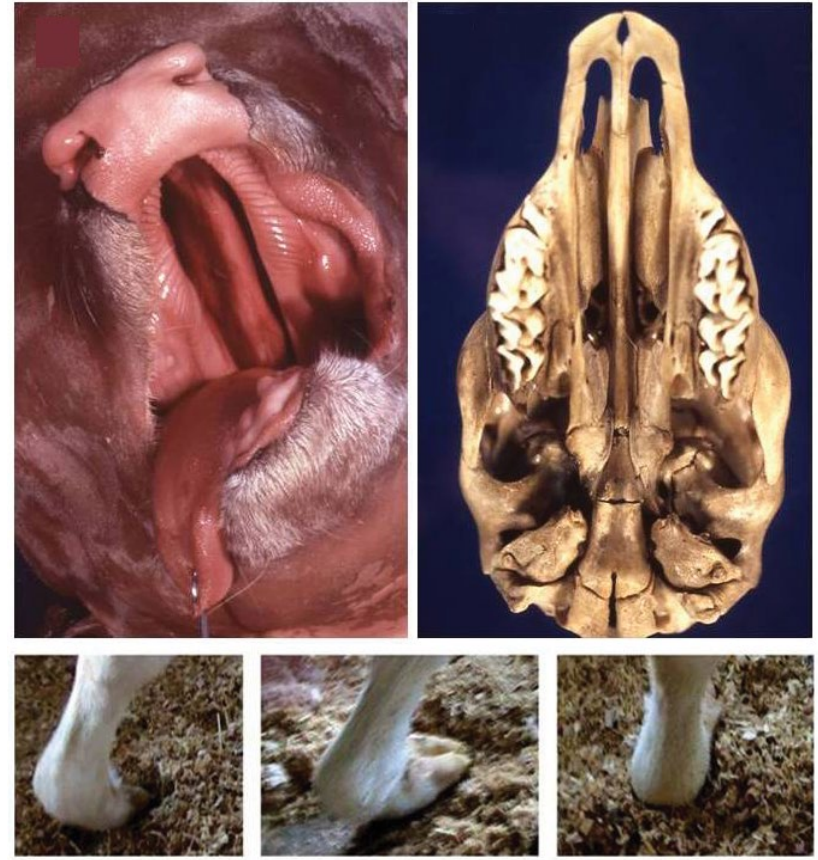

Figure 3: Top, ventral view of the roof of the oral cavity showing a typical case of cleft palate or palatoschisis in cattle. Bottom, frontal and lateral views of congenital flexed pastern in cattle.

dogs have undergone a strong artificial selection [94,95], which is the cause of molecular genetic changes and mutations in individual lineages $[96,97]$.

\section{Concluding Remarks}

In the globalized and interconnected world, we live, it is not surprising that Virchow's initial idea has deeply rooted and, after that idea, new concepts have emerged. In addition to pointing out the close relationship between human and veterinary medicine, one of the aims of the more recent initiatives has been to broaden the scope of "one medicine" to the environment, the economy, the society, the psychology, and many others. There is a lot of information addressing these matters, published by different institutions, particularly international organisms (WHO, OIE, FAO, AMA, AVMA), but within the published data, malformations or developmental anomalies are neither included nor mentioned.

Fully aware of the fact that the presentation of DA has a huge significance in health and that a high percentage of malformations are common to human and animals, it is of utmost importance to consider the theme as a crucial topic within the "one health" concept. Nonetheless, the complexity of linking DA to the "one health" concept would need to follow certain guidelines, and the proposed hereafter appear to be reasonable. Firstly, stress is put on the need to specify the type of animals involved; in the present article, we have selected domestic mammals, with the advantage that they are under a 
strict control and health surveillance. Secondly, certain types of DA, particularly those with external and macroscopical apparent signs, should be considered notifiable cases, and therefore veterinarians following a basic code of ethics should report them. Finally, it would be essential to organize administrative and support structures at local, regional and national levels, making it possible to refer-by means of the corresponding application formall diagnosed cases; in other words, a robust network of information might be required.

Difficulties linked to the proposal made need to be addressed, among other reasons, because it is a requirement of the medical science of the XXI century. The overspecialization of knowledge and the globalization are, to some extent, divergent, but it is supposed that sooner rather than later the "one health" concept becomes a reality [98], including the different types of DA.

\section{Acknowledgements}

I thank D. Salazar, N. Vandenberghe and P. Sánchez for intellectual support and helpful comments, all the vet practitioners who sent us different cases of malformations, the students who were especially interested in the subject, providing us with strong motivation to write the paper, and J. Murray for revising the final English version. Private financial support is gratefully acknowledged. I regret not having been able to cite all of the papers that have contributed to this field. The comments of three anonymous reviewers improved the clarity of the manuscript.

\section{Supplementary Appendix}

Supplementary Appendix associated with this article can be found in the online version.

\section{References}

1. Zinsstag J, Schelling E, Wyss K, et al. (2005) Potential of cooperation between human and animal health to strengthen health systems. Lancet 366: 2142-2145.

2. Enserink M (2007) Initiative aims to merge animal and human health science to benefit both. Science 316: 1553.

3. Zinsstag J, Schelling E, Bonfoh B, et al. (2009) Towards a 'One Health' research and application tool box. Vet Ital 45 : 121-133.

4. http://onehealthinitiative.com

5. http://www.who.int/mediacentre/en/

6. http://www.oneworldonehealth.org/

7. Taylor LH, Latham SM, Woolhouse ME (2001) Risk factors for human disease emergence. Philos Trans R Soc Lond B Biol Sci 356: 983-989.

8. Krauss H, Weber A, Appel M, et al. (2003) Zoonoses: infectious diseases transmissible from animals to humans. ( $3^{\text {rd }}$ edn), American Society for Microbiology, Washington.

9. Kahn LH, Kaplan B, Steele JH (2007) Confronting zoonoses through closer collaboration between medicine and veterinary medicine (as 'one medicine'). Vet Ital 43: 5-19.

10. Messenger AM, Barnes AN, Gray CG (2014) Reverse zoonotic disease transmission (zooanthroponosis): a systematic review of seldom-documented human biological threats to animals. PLoS One 9: e89055.

11. Bradbury G (2015) Ensuring animal welfare is at the heart of research. Vet Rec 176.

12. Kirk AD, Malchesky PS, Shapiro R, et al. (2016) Introducing the Wiley transplant peer review network. Am J Transplant 16: 2505-2507.

13. Mahou R, Passemard S, Carvello M, et al. (2016) Contribution of polymeric materials to progress in xenotransplantation of microencapsulated cells: a review. Xenotransplantation 23: 179-201.

14. Cooper DK, Dou KF, Tao KS, et al. (2016) Pig liver xenotransplantation: A review of progress toward the clinic. Transplantation 100: 2039-2047.

15. Hawthorne WJ, Lew AM, Thomas HE (2016) Genetic strategies to bring islet xenotransplantation to the clinic. Curr Opin Organ Transplant 21: 476-483.

16. Niemann H, Petersen B (2016) The production of multi-transgenic pigs: update and perspectives for xenotransplantation. Transgenic Res 25: 361-374.

17. http://genome.ucsc.edu/

18. http://www.ensembl.org/index.html

19. Priester WA, Glass AG, Waggoner NS (1970) Congenital defects in domesticated animals: general considerations. Am J Vet Res 31: 1871-1879.

20. Hamori D (1983) Constitutional disorders and hereditary diseases in domestic animals. Elsevier Scientific Pub, Amsterdam, New York.

21. Epstein CJ (2008) Human Malformations and their genetic basis. In: Epstein CJ, Erickson RP, Wynshaw-Boris A, Inborn errors of development. ( $2^{\text {nd }}$ edn), Oxford University Press, New York.

22. Kumar P, Burton BK (2008) Congenital malformations: Evidence-based evaluation and management. McGraw Hill, New York.

23. Saunders LZ (2000) Virchow's contributions to veterinary medicine: celebrated then, forgotten now. Vet Pathol 37: 199-207.

24. Dunlop RH, Williams DJ (1996) Veterinary medicine: an illustrated history. ( $1^{\text {st }}$ edn), Mosby, New York.

25. Dukes TW (2000) That other branch of medicine: an historiography of veterinary medicine from Canadian perspective. Can Bull Med Hist 17: 229-243.

26. Schwabe CW (1984) Veterinary Medicine and Human Health. ( $3^{\text {rd }}$ edn), Williams \& Wilkins, Baltimore, London.

27. American Veterinary Medical Association (2008) Schools/ Colleges of Veterinary Medicine (Accreditation Status as of July 2005). In: Membership Directory and Resource Manual 2006. AVMA, Division of Membership and Field Services, Shaumburg, Illinois, 181-198.

28. Buttke DE (2011) Toxicology, environmental health, and the "one health" concept. J Med Toxicol 7: 329-332. 
Citation: Salazar I (2017) Developmental Anomalies in Domestic Mammals and the One Health Concept. Stud Anat Physiol 1(1):5-12

29. Waltner Toews D (2009) Eco-Health: a primer for veterinarians. Can Vet J 50: 519-521.

30. Nielsen NO, Waltner Toews D, Nishi JS, et al. (2012) Whither ecosystem health and ecological medicine in veterinary medicine and education. Can Vet J 53: 747-753.

31. Degeling C, Johnson J, Kerridge I, et al. (2015) Implementing a One Health approach to emerging infectious disease: reflections on the socio-political, ethical and legal dimensions. BMC Public Health 15: 1307.

32. Atlas RM, Maloy S (2014) The Future of One Health. Microbiol Spectr 2.

33. Lerner H, Berg C (2015) The concept of health in one health and some practical implications for research and education: what is one health? Infect Ecol Epidemiol 5.

34. Kingsley P, Taylor EM (2017) One Health: competing perspectives in an emerging field. Parasitology 144: 7-14.

35. Zinsstag J (2012) Convergence of EcoHealth and One Health. Ecohealth 9: 371-373.

36. Zinsstag J (2016) One Health: EcoHealth 2016: Welcome from the President of the International Association for Ecology and Health. Ecohealth 13: 613-614.

37. Gibbs SE, Gibbs EP (2013) The historical, present, and future role of veterinarians in One Health. Curr Top Microbiol Immunol 365: 31-47.

38. Gibbs EP (2014) The evolution of One Health: a decade of progress and challenges for the future. Vet Rec 174: 85-91.

39. Zinsstag J, Schelling E, Waltner Toews D, et al. (2015) One health: the theory and practice of integrated health approaches. CABI.

40. Salazar I (2016) Embriología veterinaria. (2a edn), Servicio de Publicaciones e Intercambio Científico, Universidad de Santiago de Compostela, España.

41. Tuchmann-Duplessis H (1970) Embriología: Cuadernos prácticos. Toray-Mason, Barcelona.

42. Rohen JW, Lütjen-Drecoll E (2008) Embriologia funcional. ( $3^{\text {rd }}$ edn), Editorial Medica Panamericana, Buenos Aires, Argentina.

43. Flores V (2015) Embriología Humana. Bases moleculares y celulares de la histogénesis, la morfogénesis y las alteraciones del desarrollo. Orientada a la formación médica. Editorial Médica Panamericana, Buenos Aires, Argentina.

44. Sadler TW (2015) Langman's medical embryology. $\left(13^{\text {th }}\right.$ edn), Wolters Kluwer Health, Philadelphia, USA.

45. Zietzschmann O, Krölling O (1955) Lehrbuch der entwicklungsgeschichte der haustiere. ( $2^{\text {nd }}$ edn), Paul Parey, Berlin, Germany.

46. Noden DM, de Lahunta A (1985) The embryology of domestic animals: Developmental mechanisms and malformations. Williams \& Wilkins, Baltimore, London.

47. McGeady TA, Quinn PJ, Fitzpatrick ES, et al. (2006) Veterinary embryology. Blackwell Publishing, Oxford.

48. Hyttel P, Sinowatz F, Vejlsted M, et al. (2010) Essentials of domestic animals embryology. Saunders, Edinburgh.

49. Gilbert SF (2000) Developmental biology. ( $6^{\text {th }}$ edn), Sinauer Associates, Sunderland, Massachusetts.
50. Jenkins CD (1993) Selection and the evolution of genetic life cycles. Genetics 133: 401-410.

51. Kondrashov AS (1997) Evolutionary genetics of life cycles. Ann Rev Ecol Syst 28: 391-435.

52. Griffiths AJF, Wessler SR, Lewontin RC, et al. (2005) An Introduction to Genetic Analysis. ( $8^{\text {th }}$ edn), Freeman \& Co Ltd, New York.

53. Alberts B, Johnson A, Lewis J, et al. (2015) Molecular biology of the cell. (6 $6^{\text {th }}$ edn), Garland Science, New York.

54. Bowman JL, Sakakibara K, Furumizu C, et al. (2016) Evolution in the cycles of life. Annu Rev Genet 50: 133-154.

55. Brachet J, Alexandre H (1986) Introduction to molecular embryology. ( $2^{\text {nd }}$ edn), Springer-Verlag Berlin Heidelberg.

56. Barry JM (2002) Molecular embryology: How molecules give birth to animals. Taylor \& Francis, New York.

57. Lewandoski M (2016) Mouse molecular embryology: Methods and protocols. Humana Press, New York.

58. Turnpenny PD, Ellard S (2012) Emery's elements of medical genetics. (14 ${ }^{\text {th }}$ edn), Churchill Livingstone, Philadelphia.

59. Federative International Programme on Anatomical Terminologies (FIPAT) (2013) Terminologia Embryologica. International Embryological Terminology. Thieme Verlag, Stuttgart.

60. International Committee on Veterinary Embryological Nomenclature (2006) Nomina Embryologica Veterinaria. (2 edn), Universiteit Gent, Belgium.

61. Carey JC (2009) Editorial comment: Editor's foreword to a special issue "Elements of Morphology: Standard Terminology". Am J Med Genet 149A.

62. Holmes LB (2012) Common malformations. Oxford University Press, New York, 109-115.

63. Special article (1974) Classification and nomenclature of malformations. Lancet 1: 798.

64. Smith DW (1975) Classification, nomenclature, and naming of morphologic defects. J Pediatr 87: 162-164.

65. Spranger J, Benirschke K, Hall JG, et al. (1982) Errors of morphogenesis: Concepts and terms. Recommendations of an International Working Group. J Pediatr 100: 160-165.

66. Khoury MJ, Moore CA, Evans JA (1994) On the use of the term "syndrome" in clinical genetics and birth defects epidemiology. Am J Med Genet 49: 26-28.

67. Martinez-Frias ML, Frias L, Opitz JM (1998) Errors of morphogenesis and developmental field theory. Am J Med Genet 76: 291-296.

68. Hennekam RC, Biesecker LG, Allanson JE, et al. (2013) Elements of morphology: general terms for congenital anomalies. Am J Med Genet A 161A: 2726-2733.

69. https://www.imdatabases.com/

70. Kay HH, Nelson DM, Wang Y (2011) The placenta: From development to disease. Wiley-Blackwell, Oxford.

71. Parolini O (2016) Placenta: The Tree of life. CRC Press, Boca Raton, Florida.

72. Moura E, Pimpao CT (2012) Veterinary dysmorphology. In: Perez-Marin CC, A Bird's-Eye View of Veterinary Medicine. InTech. 
73. Nicholas FW, Wade CM (2006) Canine genetics: A very Special Issue. Vet J 189: 123-125.

74. Wayne RK, Ostrander EA (2007) Lessons learned from the dog genome. Trends in Genet 23: 557-567.

75. Parker HG (2012) Genomic analyses of modern dog breeds. Mamm Genome 23: 19-27.

76. Parker HG, Shearin AL, Ostrander EA (2010) Man's best friend becomes biology's best in show: genome analyses in the domestic dog. Annu Rev Genet 44: 309-336.

77. Shearin AL, Ostrander EA (2010) Canine morphology: hunting for genes and tracking mutations. PLoS Biol 8: e1000310.

78. Parker HG, Ostrander EA (2005) Canine genomics and genetics: Running with the pack. PLoS Genet 1: e58.

79. Tsai KL, Clark LA, Murphy KE (2007) Understanding hereditary diseases using the dog and human as companion model systems. Mamm Genome 18: 444-451.

80. Karlsson EK (2008) Leader of the pack: gene mapping in dogs and other model organisms. Nat Rev Genet 9: 713725 .

81. Ostrander EA (2012) Both ends of the leash. The human links to good dogs with bad genes. N Engl J Med 367: 636646.

82. Lander ES, Linton LM, Birren B, et al. (2001) Initial sequencing and analysis of the human genome. Nature 409: 860-921.

83. Venter JC, Adams MD, Myers EW, et al. (2001) The sequence of the human genome. Science 291: 1304-1351.

84. Lindblad-Toh K, Wade CM, Mikkelsen TS, et al. (2005) Genome sequence, comparative analysis and haplotype structure of the domestic dog. Nature 438: 803-819.

85. http://discoveryspace.upei.ca/cidd/
86. http://www.hsvma.org/assets/pdfs/guide-to-congenital-and-heritable-disorders.pdf

87. Sargan DR (2004) IDID: inherited diseases in dogs: webbased information for canine inherited disease genetics. Mamm Genome 15: 503-506.

88. http://sydney.edu.au/vetscience/lida/

89. http://omia.angis.org.au/home/

90. http://eurolupa.org

91. Lequarre AS, Andersson L, Andre C, et al. (2011) LUPA: A European initiative taking advantage of the canine genome architecture for unravelling complex disorders in both human and dogs. Vet J 189: 155-159.

92. American Kennel Club (2014) The complete dog book. Official breed standards and all-new profiles for 200 Breed. (21 $1^{\text {st }}$ edn), I-5 Press, New York.

93. http://www.pedigreedatabase.com/switch_breed.html

94. Cagan A, Blass T (2016) Identification of genomic variants putatively targeted by selection during dog domestication. BMC Evol Biol 16: 10.

95. Marsden CD, Ortega-Del Vecchyo D, O'Brien DP, et al. (2016) Bottlenecks and selective sweeps during domestication have increased deleterious genetic variation in dogs. Proc Natl Acad Sci USA 113: 152-157.

96. Wayne RK, von Holdt BM (2012) Evolutionary genomics of dog domestication. Mamm Genome 23: 3-18.

97. Schoenebeck JJ, Ostrander EA (2013) The genetic of canine skull shape variation. Genetics 193: 317-325.

98. Cardiff RD, Ward JM, Barthold SW (2008) 'One medicineone pathology': are veterinary and human pathology prepared? Lab Invest 88: 18-26. 